\title{
BACK AND NECK PAIN DISABILITY AND UPPER LIMB SYMPTOMS OF HOME HEALTHCARE WORKERS: A CASE-CONTROL STUDY FROM NORTHERN ITALY
}

\author{
MATTEO RICCÒ ${ }^{1}$, FEDERICA PEZZETTI ${ }^{2}$, and CARLO SIGNORELLI ${ }^{2}$ \\ ${ }^{1}$ Provincial Agency for Health Services of the Autonomous Province of Trento, Trento, Italy \\ Department of Prevention, Occupational Health and Safety Unit \\ ${ }^{2}$ University of Parma, Parma, Italy \\ Specialization School in Hygiene and Public Health, Department of Biomedical, Biotechnological and Translational \\ Sciences
}

\begin{abstract}
Objectives: Work-related musculoskeletal disorders (MSD) are quite frequent in healthcare workers (HCWs), but data about MSD in home-based healthcare workers (HHWs) are lacking. In this study we describe the prevalence of MSD among Italian HHWs. Material and Methods: A case-control study was carried out among 300 random-selected female HCWs, the sample comprising $100 \mathrm{HHWs}, 100 \mathrm{HCWs}$ with a low exposure to patient handling (MAPO - Movimentazione e Assistenza Pazienti Ospedalizzati - Movement and Assistance of Hospital Patients index 0-5) and 100 HCWs with high exposure to patient handling (MAPO index $\geq 5.01$ ). As a negative control group, 200 visual display unit workers were also randomly selected. Musculoskeletal disorder cases were collected using a standardized case definition. A multivariate logistic regression analysis was performed comparing the MSD prevalence in the 4 groups. Results: The overall prevalence of MSD was $17 \%$ in the reference group and $28.3 \%$ for HCWs. HHWs and HCWs with MAPO index $\geq 5.01$ had similar prevalence of neck pain ( $9 \%$ and $11 \%$, respectively), whereas lumbosacral pain prevalence was higher in the HHWs group (31\%), with similar results in residential HCWs groups (21\% in MAPO index $0-5$ group and $25 \%$ in MAPO index $\geq 5.01$ group). HCWs of group MAPO index $\geq 5.01$ and HHWs showed the higher prevalence of upper limb complaints, with a prevalence of $20 \%$ and $10 \%$, respectively. In multivariate regression analysis, prevalence of MSD complaints was quite similar in HHWs (adjusted odds ratio $(\mathrm{OR})=2.335,95 \%$ confidence interval $(\mathrm{CI}): 1.318-4.138)$ and in HCWs of the group MAPO $\geq 5.01$ $\left(\mathrm{OR}_{\text {adi }}=2.729,95 \% \mathrm{CI}: 1.552-4.797\right)$. Conclusions: The prevalence of MSD in the examined HCWs was relatively high, with HHWs appearing as a particularly high-risk group for lumbosacral back pain. In higher exposed HCWs, upper-limb symptoms were particularly frequent, probably reflecting the different tasks required to manage residential and homebased patients. In conclusion, this study reaffirms the high prevalence of MSD in HHWs, seemly similar to high-risk residential groups. Int J Occup Med Environ Health 2017;30(2):291-304
\end{abstract}

Key words:

Occupational health, Females, Low back pain - diagnosis, Moving and lifting patients, Lifting - adverse effects, Musculoskeletal diseases - epidemiology

Received: March 10, 2015. Accepted: February 2, 2016.

Corresponding author: M. Ricco, Provincial Agency for Health Services of the Autonomous Province of Trento, Department of Prevention, Occupational Health and Safety Unit, Viale Verona SNC C/O Big Center corpo A, piano 1, 38123 Trento, Italy (e-mail: mricco2000@gmail.com). 


\section{INTRODUCTION}

Musculoskeletal disorders (MSD) and in particular neck and back pain (NBP) and upper-limb symptoms (ULS) are a common health problem with a multifactorial aetiology [1-5]: their prevalence among healthcare workers (HCWs) has been documented in many studies as even higher than in general population [6-8], as HCWs have been found at higher risk for MSD and mainly NBP than personnel in even higher physical demanding occupations, such as construction workers or garbage collectors [9]. Healthcare workers frequently complain of chronic/ persistent MSD [10,11], which have been reported as the main cause for sick leave in nursing staff [12]. In 1996, Hignett determined that nurses have a point prevalence of NBP of $17 \%$, an annual prevalence of $40-50 \%$ and a lifetime prevalence of $35-80 \%$ [13], with a higher risk for nurses engaging in frequent patient handling. These results have been subsequently reiterated in various studies, with risk estimates ranging 1.2-5.5 depending on definitions [14]. Also the prevalence of ULS appears as relevant, ranging $43-53 \%$ in the various studies [6].

Patient-handling activities are considered to be the main cause of MSD among healthcare workers [6,10,15]. The activities during patient handling often include lifting, pushing/pulling, transferring and repositioning of patients, causing awkward back posture and requiring application of high forces by the healthcare worker [16-19]. In contrast to the standardized, usually well-controlled and well-equipped environment of institutions, in home care settings all these activities are performed without consistent assistances, in environments that are often inappropriate [20,21] and associated with high risk of work-related musculoskeletal injuries [22,23]. The risk is usually increased by the small dwelling spaces, the slippery surfaces of the bathrooms, and the circumstance that HCWs often perform that unpredictable and uncontrollable, physically demanding work alone [14,21,22].

While the high incidence and prevalence of MSD in hospital staff have attracted the deserved attention of many researchers, patient handling as a risk factor for MSD in home care settings had been for long time neglected by occupational health researchers. An earlier work by Ono et al. [24] suggested that home healthcare workers (HHWs) could have a very low rate of musculoskeletal complaints (1.51-1.92\% on annual basis).

These results have been contradicted by subsequent studies. Knibbe and Friele [25] reported an incidence rate of $66.8 \%$ for community nurses over a 12 month period, and their results are consistent with Moens et al. [26], reporting an annual NBP incidence of $63 \%$ in 4723 Belgian HHWs. In a more recent study, Cheung et al. [21] identified a 12-month prevalence of NBP of $71.2 \%$ in HHWs, suggesting physical risk factors, static postures and psychological job demands as main determinants. Eventually, there is a substantial agreement that patient-handling activities in this setting may be at specifically high risk for MSD. However, many uncertainties still remain [14,21]. First of all, national policies on home healthcare vary considerably, with some countries focusing on basic care for all (e.g., Scandinavian countries) and others (e.g., France, Germany, Italy) emphasizing intensive help and care for the few individuals with the highest level of need [21,27]. Physical demand is therefore very variable and heterogeneous among various countries, explaining the apparently contradictory conclusions from the European Nurses' Early Exit (NEXT) Study, where a lower exposure for HHWs was apparently identified [12].

Second, the range of tasks, types and level of activities undertaken by HHW is very difficult to determine [21]. For example, in most European countries, nurses evaluate people who receive home care, develop care plans, provide skilled nursing care, determine whether other services are required [26-28], with home care assistants performing basic but also most physically demanding duties. However, this is not a constant feature and it is far from uncommon identifying nursing staff performing household duties. 
Eventually, conventional risk assessment methods for patient handling are not applicable in the home care settings: as recently stated in the Technical Report ISO/ TR 12296 [29], the more accurate risk assessment methods like PTAI (Patient Transfer Assessment Instrument), MAPO (Movimentazione e Assistenza Pazienti Ospedalizzati - Movement and Assistance of Hospital Patients), TilThermometer and Dortmund can not be efficiently applied. This limitation is particularly annoying in the southern-Europe context, particularly in Italy and Spain, where the Movement and Assistance of Hospital Patients (MAPO) risk assessment method is usually applied in residential units [30,31], being a familiar tool not only for occupational physicians and more in general for health and safety professionals, but also in public health settings, where its analytical quickness as well as its effectiveness in planning preventive actions has been extensively appreciated for a more cost-effective management of HCWs.

Hence, investigations about the occurrence of MSD among HHWs are in need in order to achieve a better depiction of the magnitude of this issue: in this study, therefore, we present an assessment of MSD prevalence in Italian HHWs. Moreover, we evaluated the occurrence of NBP/ULS in HHWs in confront with residential HCWs as defined by MAPO risk assessment tool. Previous reports in residential units identified a well distinct cut-off value of MAPO index $\geq 5.01$ for patients at higher risk of MSD [31]: the secondary aim of our study was then to assess whether HHWs could be matched to lower or higher risk group regarding NBP/ULS prevalence.

\section{MATERIAL AND METHODS}

\section{Subjects}

A total of 1653 subjects (1001 HCWs including 254 HHWs, and 652 administrative workers) active in 8 private healthcare companies based in the Emilia Romagna Region (Northern Italy) between January 2012 and
December 2013 underwent annual compulsory medical examination. Personal and clinical data were collected, with basic demographics comprising: age, sex, height and weight (body mass index - BMI was calculated as weight/ stature $^{2}$ ), years of education, previous pregnancies, year of practice and working, smoking history (never vs. ever) and significant morbidity information (such as diabetes, hypertension, cancer, rheumatoid diseases, previous traumatic musculoskeletal disorders, etc.).

\section{Informed consent}

Because of the retrospective design of the study, no preliminary evaluation by the Ethical Committee was necessary. However, all participants gave their written consent before the collection of clinical and personal data.

\section{Prevalence of musculoskeletal morbidity}

The Ergonomics of Posture and Movement (EPM) research unit medical questionnaire was compiled by the occupational physician, collecting information on pain, aches or discomfort in the back, neck and shoulders. The questionnaire was previously validated, has been found appropriate for use in Italian working population, and is commonly used by occupational physicians in Italy as musculoskeletal anamnestic utility [32]. All patients received a physical examination with specific attention to musculoskeletal signs and symptoms [33]. Results were recorded and classified following the methodology of the EPM, since 2004 recognized by Italian Society for Occupational Medicine and Industrial Hygiene (Società Italiana di Medicina del Lavoro ed Igiene Industriale - SIMLII) in its guidelines on prevention of work-related musculoskeletal disorders (Table 1) [30,34,35].

\section{Risk assessment}

Movement and Assistance of Hospital Patients (MAPO) method is a semi-quantitative methodology for risk assessment of patient handling in residential units. This 
Table 1. Working definition and classification of work-related musculoskeletal disease of back, neck and upper limb*

\begin{tabular}{|c|c|}
\hline Musculoskeletal disorders & Definition \\
\hline \multicolumn{2}{|l|}{ Neck/back pain } \\
\hline grade 1 & $\begin{array}{l}\text { discomfort in the back or in the neck with or without radiation into the leg to below to knee for } \\
\text { at least } 1 \text { day during the preceding } 12 \text { months; physical examination negative }\end{array}$ \\
\hline grade 2 & grade 1 and pain elicited by palpation of paravertebral muscle and/or spinal apophysis \\
\hline grade 3 & $\begin{array}{l}\text { grade } 2 \text { and positivity of direct and/or indirect Lasegue sign, with/without pain at mobilization } \\
\text { (active/passive) }\end{array}$ \\
\hline \multirow[t]{3}{*}{ Upper-limb symptoms positive } & persistent pain in at least 1 location (shoulder, elbow, wrist/hand) of the upper limb \\
\hline & $\begin{array}{l}\text { or } \\
\text { pain in at least } 1 \text { location (shoulder, elbow, wrist/hand) of the upper limb, lasting at least } 1 \text { week } \\
\text { during the preceding } 12 \text { months }\end{array}$ \\
\hline & $\begin{array}{l}\text { or } \\
\text { pain in at least } 1 \text { location (shoulder, elbow, wrist/hand) of the upper limb, lasting at least } 1 \text { day/ } \\
\text { month during the preceding } 12 \text { months }\end{array}$ \\
\hline
\end{tabular}

* Based on: Battevi et al. [30]; Violante et al. [34]; Colombini et al. [35].

method is widely applied not only in Italy but also in Spain and has been acknowledged by the Technical Report ISO/ TR 12296 [29] as a useful tool for planning effective preventive actions, including the choice of adequate equipment and the right number of equipment related to the mobility of the patients. As previously described [30,31], MAPO index summarizes the level of exposure to patient handling by the following mathematical expression:

$$
\mathrm{MAPO}=(\mathrm{NC} / \mathrm{Op} \times \mathrm{LF}+\mathrm{PC} / \mathrm{Op} \times \mathrm{AF}) \times \mathrm{WF} \times \mathrm{EF} \times \mathrm{TF}
$$

where:

$\mathrm{NC/Op}$ - the relationship between non-cooperative patients and the operators present in the working shifts,

$\mathrm{LF}$ - the lifting factor,

$\mathrm{PC} / \mathrm{Op}$ - the ratio of partially cooperative patients to the operators present,

$\mathrm{AF}$ - the minor aids factor,

$\mathrm{WF}$ - the wheelchair factor,

$\mathrm{EF}$ - the environment factor,

$\mathrm{TF}$ - the training factor.
Factors NC, PC, Op, LF, AF and TF are collected during an interview with ward head or the senior ward operator, WF and EF can be assessed only via a ward inspection.

\section{Exclusion criteria and randomization}

Subjects of male sex, younger than 25-year old, with a working age $<2$ years, a BMI $\geq 30 \mathrm{~kg} / \mathrm{m}^{2}$, neurological deficits, spinal cord compression, severe structural deformity, osteoporosis, instability, previous traumatic musculoskeletal disorders, severe cardiovascular, respiratory, autoimmune or metabolic disease, cancer or previous spinal surgery were excluded from this study. Moreover, controls from administrative personnel with a personal occupational history of manual lifting were also excluded. A sample of 500 workers was then collected through a stratified random sampling from all the involved companies. The study population was organized in 3 groups of occupational exposure:

- professional nurses employed in home care services $(\mathrm{N}=100$, cases $)$; 
- professionals employed in nursing homes or as hospitalbased nurses ( $N=200$, positive controls). In accordance with the results of MAPO risk assessment method, this control group was further subdivided in two subgroups including workers having high patient handling strain (MAPO index $\geq 5.01, \mathrm{~N}=100$ ) and workers with low professional exposure (MAPO index $0-5, \mathrm{~N}=100$ );

- subjects employed as administrative workers $(\mathrm{N}=200$, reference).

\section{Statistical analysis}

Descriptive analyses were examined for all variables under study. Comparison between residential HCWs, HHWs and reference groups were conducted using analysis of variance (ANOVA) for continuous variables, with post hoc Tukey's test, and $\mathrm{Chi}^{2}$ test for dichotomous variables.

The prevalence of MSD in the exposure groups was compared through a logistic regression analysis, with calculation of odds ratio (OR) with $95 \%$ confidence intervals (CI). For each subject included into the study, the response variables (NBP, ULS) were considered as binary: presence of the event (Table 1) and absence of the event. In case of ULS, the presence of symptoms, irrespective of the site or side (left, right, bilateral) involved, identified the presence of the event. Dichotomous variables showing a correlation of at least 0.02 with NBP pain were considered for multiple logistic regression analysis, with consequent calculation of adjusted $\mathrm{OR}\left(\mathrm{OR}_{\mathrm{adj}}\right)$.

All statistical analyses were performed using version 22.0 of the IBM SPSS Statistics for Mac OsX (SPSS, IBM Corp. released 2013; version 22.0, Armonk, NY, USA).

\section{RESULTS}

The characteristics of the participants are summarized in Table 2. In general, age and working age did not significantly differ among the exposure groups (ANOVA: $\mathrm{p}=0.212$, and 0.206 , respectively). Employment rate in patient handling (h/week) was significantly lower in home care workers in confront with the other groups of HCWs, and the group having MAPO index $\geq 5.01$ was the most

Table 2. Main personal data of study groups - residential healthcare workers (HCWs) subdivided by exposure as assessed by MAPO [29-31] and home-based healthcare workers (HHWs) - and controls (administrative workers)

\begin{tabular}{|c|c|c|c|c|c|}
\hline \multirow{3}{*}{ Characteristics } & \multicolumn{4}{|c|}{$\begin{array}{l}\text { Exposure group } \\
\quad(\mathrm{N}=500)\end{array}$} & \multirow{3}{*}{$\mathrm{p}$} \\
\hline & \multirow{2}{*}{$\begin{array}{c}\text { administrative } \\
\text { workers } \\
\text { (reference) } \\
(\mathrm{N}=200)\end{array}$} & \multicolumn{2}{|c|}{ HCWs } & \multirow[b]{2}{*}{$\begin{array}{l}\text { HHWs } \\
(\mathrm{N}=100)\end{array}$} & \\
\hline & & $\begin{array}{c}\text { MAPO 0-5 } \\
(\mathrm{N}=100)\end{array}$ & $\begin{array}{c}\text { MAPO } \geq 5.01 \\
\quad(\mathrm{~N}=100)\end{array}$ & & \\
\hline Age [years] $(\mathrm{M} \pm \mathrm{SD})$ & $41.8 \pm 9.7$ & $42.5 \pm 8.7$ & $41.7 \pm 8.9$ & $44.1 \pm 10.1$ & 0.212 \\
\hline$<30$ years $[\mathrm{n}]$ & 17 & 14 & 4 & 8 & \\
\hline $30-39$ years $[n]$ & 87 & 21 & 45 & 28 & \\
\hline $40-49$ years $[n]$ & 45 & 42 & 37 & 29 & \\
\hline $50-59$ years $[\mathrm{n}]$ & 37 & 21 & 8 & 31 & \\
\hline$\geq 60$ years $[n]$ & 14 & 2 & 6 & 4 & \\
\hline Working age [years] $(\mathrm{M} \pm \mathrm{SD})$ & $17.3 \pm 7.9$ & $17.3 \pm 9.5$ & $16.2 \pm 8.3$ & $17.7 \pm 12.5$ & 0.206 \\
\hline $\begin{array}{l}\text { Employment in patient handling } \\
{[\mathrm{h} / \text { weeks }](\mathrm{M} \pm \mathrm{SD})}\end{array}$ & n.a. & $27.9 \pm 2.4$ & $30.2 \pm 2.1$ & $24.4 \pm 2.8$ & $<0.0001$ \\
\hline Smoking history (yes/no) [n (\%)] & $57(28.5)$ & $36(36.0)$ & $39(39.0)$ & $42(42.0)$ & 0.085 \\
\hline
\end{tabular}


Table 2. Main personal data of study groups - residential healthcare workers (HCWs) subdivided by exposure as assessed by MAPO [29-31] and home-based healthcare workers (HHWs) - and controls (administrative workers) - cont.

\begin{tabular}{|c|c|c|c|c|c|}
\hline \multirow{3}{*}{ Characteristics } & \multicolumn{4}{|c|}{$\begin{array}{l}\text { Exposure group } \\
\quad(\mathrm{N}=500)\end{array}$} & \multirow{3}{*}{$\mathrm{p}$} \\
\hline & \multirow{2}{*}{$\begin{array}{c}\text { administrative } \\
\text { workers } \\
\text { (reference) } \\
(\mathrm{N}=200)\end{array}$} & \multicolumn{2}{|c|}{ HCWs } & \multirow[b]{2}{*}{$\begin{array}{c}\text { HHWs } \\
(\mathrm{N}=100)\end{array}$} & \\
\hline & & $\begin{array}{c}\text { MAPO 0-5 } \\
(\mathrm{N}=100)\end{array}$ & $\begin{array}{c}\text { MAPO } \geq 5.01 \\
\quad(\mathrm{~N}=100)\end{array}$ & & \\
\hline Previous pregnancies (any) $[\mathrm{n}(\%)]$ & $100(50.0)$ & $48(48.0)$ & $63(63.0)$ & $61(61.0)$ & 0.047 \\
\hline WHO region of origin $[\mathrm{n}(\%)]$ & & & & & $<0.0001$ \\
\hline Europe (EUR) & $196(98.0)$ & $92(92.0)$ & $95(95.0)$ & $98(98.0)$ & \\
\hline of Italian descent & $196(98.0)$ & $84(84.0)$ & $88(88.0)$ & $89(89.0)$ & \\
\hline Eastern Mediterranean (EMR) & $1(0.5)$ & $1(1.0)$ & $1(1.0)$ & $0(0.0)$ & \\
\hline Africa (AFR) & $0(0.0)$ & $1(1.0)$ & $1(1.0)$ & $1(1.0)$ & \\
\hline the Americas (AMR) & $3(1.5)$ & $5(5.0)$ & $2(2.0)$ & $1(1.0)$ & \\
\hline South-East Asia (SEAR) & $0(0.0)$ & $1(1.0)$ & $1(1.0)$ & $0(0.0)$ & \\
\hline
\end{tabular}

MAPO (Movimentazione e Assistenza Pazienti Ospedalizzati) - Movement and Assistance of Hospital Patients index; WHO - World Health Organization.

M - mean; SD - standard deviation; n.a. - not applicable.

exposed group (ANOVA: $\mathrm{p}<0.0001$; post hoc Tukey's test $<0.01)$. Because MAPO index is strictly associated with patient handling, and home care workers spend a consistent part of working shift on the road (i.e., riding a bus or a car, walking, standing, or climbing stairs), this difference was actually expected.

In general, cumulative prevalence of MSD morbidity was $17 \%$ in the reference group and $28.3 \%$ in exposed groups (Table 3): in particular, a prevalence of $20 \%$ was identified in the HCWs group with MAPO index $0-5$ and $34 \%$ in the group with MAPO index $\geq 5.01$; in HHWs, the cumulative prevalence was $31 \%$.

Among the groups, MSD morbidity rose with the age of subjects, increasing from $11.6 \%$ in subjects $<30$ yearold to $42.3 \%$ in participants $\geq 60$ year-old. In particular, HCWs with MAPO index $\geq 1.51$ and HHWs $\geq 50$ year old reported a cumulative MSD prevalence of $54.3 \%$ and $50 \%$, respectively.

Focusing on the affected locations, HHWs and HCWs with MAPO index $\geq 5.01$ had similar prevalence of NBP in cervical region (9\% and $11 \%$, respectively), with a reduced prevalence in HCWs MAPO 0-5 group (6\%).

At lumbosacral level, prevalence of NBP was similar in both residential HCWs groups (21\% in MAPO index 0-5 group and $25 \%$ in MAPO index $\geq 5.01$ group) and higher in the HHWs group (31\%). Moreover, HHWs reported a prevalence of NBP grade 2-3 cases (23/31 cases, 74.2\%) with $17 / 31$ cases $(55.4 \%)$ grade 3 cases, that is significantly higher than residential groups, i.e., $2 / 21$ cases $(9.5 \%)$ and $8 / 25$ cases (32\%) for MAPO index $0-5$ and $\geq 5.01$, respectively.

In regression analysis (Table 4), MSD complaints were more frequent in HHWs and HCWs of the group MAPO $\geq 5.01(\mathrm{OR}=2.194,95 \% \mathrm{CI}: 1.251-3.847$ and $\mathrm{OR}=2.515$, 95\% CI: 1.445-4.378) than in residential HCWs with lower MAPO (OR $=1.221,95 \%$ CI: 0.661-2.254) and reference groups.

When a more discrete analysis was performed, by discriminating among cervical, dorsal and lumbosacral level of NBP, a similar prevalence of complaints was identified 
Table 3. Prevalence of musculoskeletal disorders (MSD)* in study groups - residential healthcare workers (HCWs) subdivided by exposure as assessed by MAPO [29-31] and home-based healthcare workers (HHWs) - and controls (administrative workers)

\begin{tabular}{|c|c|c|c|c|}
\hline \multirow{3}{*}{ Variable } & \multicolumn{4}{|c|}{$\begin{array}{l}\text { Exposure group } \\
\quad(\mathrm{N}=500)\end{array}$} \\
\hline & \multirow{2}{*}{$\begin{array}{c}\text { administrative } \\
\text { workers } \\
\text { (reference) } \\
(\mathrm{N}=200)\end{array}$} & \multicolumn{2}{|c|}{ HCWs } & \multirow[b]{2}{*}{$\begin{array}{c}\text { HHWs } \\
(\mathrm{N}=100)\end{array}$} \\
\hline & & $\begin{array}{c}\text { MAPO 0-5 } \\
(\mathrm{N}=100)\end{array}$ & $\begin{array}{c}\text { MAPO } \geq 5.01 \\
\quad(\mathrm{~N}=100)\end{array}$ & \\
\hline $\begin{array}{l}\text { Neck and back pain (NBP) and/or upper- } \\
\text { limb symptoms (ULS) [n (\%)] }\end{array}$ & $34(17)$ & $24(24)$ & $34(34)$ & $31(31)$ \\
\hline prevalence ratio* & 1.0 & 1.4 & 2.0 & 1.8 \\
\hline \multicolumn{5}{|l|}{$\begin{array}{l}\text { Musculoskeletal examination positive } \\
\text { cervical }\end{array}$} \\
\hline grade 1 [n] & 8 & 0 & 10 & 5 \\
\hline grade 2 [n] & 7 & 4 & 2 & 3 \\
\hline grade 3 [n] & 1 & 3 & 1 & 1 \\
\hline prevalence ratio* & 1.0 & 1.1 & 1.6 & 1.0 \\
\hline \multicolumn{5}{|l|}{ dorsal } \\
\hline grade 1 [n] & 1 & 0 & 2 & 3 \\
\hline grade 2 [n] & 1 & 1 & 0 & 4 \\
\hline grade 3 [n] & 2 & 0 & 0 & 0 \\
\hline prevalence ratio & 1.0 & 0.5 & 1.0 & 3.5 \\
\hline \multicolumn{5}{|l|}{ lumbosacral } \\
\hline grade $1[\mathrm{n}]$ & 9 & 2 & 11 & 8 \\
\hline grade $2[n]$ & 6 & 6 & 6 & 6 \\
\hline grade 3 [n] & 3 & 13 & 8 & 17 \\
\hline prevalence ratio** & 1.0 & 2.3 & 2.8 & 3.4 \\
\hline \multicolumn{5}{|l|}{ upper limb } \\
\hline $\mathrm{ULS}[\mathrm{n}(\%)]$ & $6(3)$ & $3(3)$ & $20(20)$ & $10(10)$ \\
\hline prevalence ratio & 1.0 & 1.0 & 6.7 & 3.3 \\
\hline shoulder [n] & 0 & 2 & 2 & 1 \\
\hline elbow [n] & 3 & 3 & 5 & 4 \\
\hline wrist/hand [n] & 5 & 1 & 21 & 11 \\
\hline
\end{tabular}

* As defined by working definition reported in Table 1 (based on: [30,34,35]).

** Prevalence ratio was calculated by assuming the events in administrative workers as the reference, and the response variable NBP and ULS as a binary one: presence or absence of the event. In case of ULS, the presence of symptoms, irrespective of the site or side (left, right, bilateral) involved identified presence of the event.

for cervical NBP (Table 4), also when confounding factors were taken in account in multivariate regression analysis. At dorsal and lumbosacral level (Table 4), HHWs showed a quite high prevalence of complaints with $\mathrm{OR}=3.688$,
95\% CI: $1.053-12.912$ and OR $=4.543$, 95\% CI: $2.387-$ 8.645 , for dorsal and lumbosacral level, respectively. The reported prevalence was significantly higher than for other HCWs groups, and also for HCWs group MAPO $\geq 5.01$ 
Table 4. Multinomial logistic regression analyses for musculoskeletal disorders (MSD) in study groups - residential healthcare workers (HCWs) subdivided by exposure as assessed by MAPO [29-31] and home-based healthcare workers (HHWs) - and controls (administrative workers)

\begin{tabular}{|c|c|c|c|c|c|c|c|c|c|}
\hline \multirow[b]{2}{*}{ Musculoskeletal disorders } & \multirow{2}{*}{$\begin{array}{c}\text { Workers } \\
(\text { total }) \\
(\mathrm{N}=500) \\
{[\mathrm{n}]}\end{array}$} & \multirow{2}{*}{$\begin{array}{c}\text { MSD } \\
\text { prevalence } \\
{[\%]}\end{array}$} & \multirow[b]{2}{*}{$\mathrm{p}$} & \multirow[b]{2}{*}{ OR } & \multicolumn{2}{|c|}{$95 \% \mathrm{CI}$} & \multirow[b]{2}{*}{$\mathrm{OR}_{\mathrm{adj}}{ }^{*}$} & \multicolumn{2}{|c|}{$95 \% \mathrm{CI}$} \\
\hline & & & & & LL & UL & & LL & UL \\
\hline \multicolumn{10}{|l|}{$\overline{\text { Any }}$} \\
\hline administrative workers (reference) & 200 & 17.0 & 1.000 & 1.000 & - & - & 1.000 & - & - \\
\hline \multicolumn{10}{|l|}{ HCWs } \\
\hline MAPO 0-5 & 100 & 24.0 & 0.524 & 1.221 & 0.661 & 2.254 & 1.374 & 0.738 & 2.557 \\
\hline MAPO $\geq 5.01$ & 100 & 34.0 & 0.001 & 2.515 & 1.445 & 4.378 & 2.729 & 1.552 & 4.797 \\
\hline HHWs & 100 & 31.0 & 0.006 & 2.194 & 1.251 & 3.847 & 2.335 & 1.318 & 4.138 \\
\hline \multicolumn{10}{|l|}{$\begin{array}{l}\text { Neck and back pain } \\
\text { cervical }\end{array}$} \\
\hline administrative workers (reference) & 200 & 7.5 & 1.000 & 1.000 & - & - & 1.000 & - & - \\
\hline \multicolumn{10}{|l|}{ HCWs } \\
\hline MAPO 0-5 & 100 & 6.0 & 0.632 & 0.787 & 0.296 & 2.095 & 0.805 & 0.299 & 2.169 \\
\hline MAPO $\geq 5.01$ & 100 & 13.0 & 0.127 & 1.843 & 0.840 & 4.041 & 1.840 & 0.828 & 4.089 \\
\hline HHWs & 100 & 9.0 & 0.652 & 1.220 & 0.514 & 2.893 & 1.221 & 0.509 & 2.934 \\
\hline \multicolumn{10}{|l|}{ dorsal } \\
\hline administrative workers (reference) & 200 & 2.0 & 1.000 & 1.000 & - & - & 1.000 & - & - \\
\hline \multicolumn{10}{|l|}{ HCWs } \\
\hline MAPO 0-5 & 100 & 1.0 & 0.532 & 0.495 & 0.055 & 4.487 & 0.506 & 0.055 & 4.637 \\
\hline MAPO $\geq 5.01$ & 100 & 2.0 & 1.000 & 1.000 & 0.180 & 5.555 & 1.043 & 0.185 & 5.891 \\
\hline HHWs & 100 & 7.0 & 0.041 & 3.688 & 1.053 & 12.912 & 3.783 & 1.057 & 13.546 \\
\hline \multicolumn{10}{|l|}{ low back } \\
\hline administrative workers (reference) & 200 & 9.0 & 1.000 & 1.000 & - & - & 1.000 & - & - \\
\hline \multicolumn{10}{|l|}{ HCWs } \\
\hline MAPO 0-5 & 100 & 21.0 & 0.005 & 2.688 & 1.358 & 5.320 & 2.912 & 1.459 & 5.813 \\
\hline MAPO $\geq 5.01$ & 100 & 24.0 & 0.001 & 3.193 & 1.638 & 6.222 & 3.323 & 1.692 & 6.524 \\
\hline HHWs & 100 & 31.0 & $<0.001$ & 4.543 & 2.387 & 8.645 & 4.671 & 2.435 & 8.957 \\
\hline \multicolumn{10}{|l|}{ Upper-limb symptoms } \\
\hline administrative workers (reference) & 200 & 3.0 & 1.000 & 1.000 & - & - & 1.000 & - & - \\
\hline \multicolumn{10}{|l|}{ HCWs } \\
\hline MAPO 0-5 & 100 & 3.0 & 1.000 & 1.000 & 0.245 & 4.084 & 0.982 & 0.238 & 4.056 \\
\hline MAPO $\geq 5.01$ & 100 & 20.0 & $<0.001$ & 8.083 & 3.130 & 20.875 & 9.323 & 3.528 & 24.641 \\
\hline HHWs & 100 & 10.0 & 0.016 & 2.194 & 1.267 & 10.190 & 3.901 & 1.353 & 11.248 \\
\hline
\end{tabular}

MAPO (Movimentazione e Assistenza Pazienti Ospedalizzati) - Movement and Assistance of Hospital Patients index.

OR - odds ratio; CI - confidence interval; LL - lower limit; UL - upper limit; $\mathrm{OR}_{\text {adj }}$ - adjusted odds ratio.

$* \mathrm{OR}_{\mathrm{adj}}$ were calculated with their respective $95 \% \mathrm{CI}$ taking in account personal confounding factors (such as smoking history, previous pregnancies and ethnic origin) not controlled by exclusion criteria. 
$(\mathrm{OR}=3.193,95 \%$ CI: $1.638-6.222$ for lumbosacral complaints and $\mathrm{OR}=1,95 \% \mathrm{CI}: 0.18-5.555)$.

Adjustment for potential confounder, as shown in Table 4, showed no relevant effect on the estimates, and confirmed the high prevalence of NBP affecting dorsal and lumbosacral level in HHWs, not only with respect to reference group, but also to the $2 \mathrm{HCW}$ groups.

Eventually, when only NBP of class 2-3 (as shown in Table 1) were evaluated in the multivariate regression analysis model (Table 5), HHWs were associated with the higher prevalence of complaints $\left(\mathrm{OR}_{\text {adj }}=3.453,95 \% \mathrm{CI}\right.$ : 1.732 6.884) followed by HCWs of MAPO group $\geq 5.01\left(\mathrm{OR}_{\mathrm{adj}}=\right.$ $3.059,95 \%$ CI: 1.517-6.169) and HCWs of MAPO group $0-5\left(\mathrm{OR}_{\text {adj }}=2.222,95 \%\right.$ CI: $\left.1.063-4.637\right)$.

Also focusing on ULS (Table 4), residential HCWs of group MAPO index $\geq 5.01$ and HHWs showed the higher prevalence of complaints, with a prevalence of 20/100 (8 of them, bilateral) and 10\% (6 of them, bilateral), respectively, in confront with the $3 / 100$ cases in the group MAPO index 0-5 (all bilateral). The more affected locations were wrist/hand $(8 \%)$ in HHWs, and the elbow (12\%) in HCWs with MAPO index $\geq 5.01$.

In regression analysis, ULS were more clearly associated with $\mathrm{HCWs}$ of group MAPO $\geq 5.01\left(\mathrm{OR}_{\mathrm{adj}}=9.323,95 \%\right.$
CI: 3.528-24.641) but also HHWs exhibited a significantly high prevalence $\left(\mathrm{OR}_{\mathrm{adj}}=3.901,95 \%\right.$ CI: $\left.1.353-11.248\right)$, with MAPO index 0-5 group and reference group showing a similar one.

\section{DISCUSSION}

As a cornerstone of the modern primary care [36,37], deinstitutionalization and community living of patients are globally increasing due to an aging population, concerns about public expenditure associated with longer hospital stay, and the rise of noncommunicable disease (e.g., mental illnesses; Alzheimer's disease; dementia; but also long-time consequences of diabetes, heart diseases, respiratory diseases, stroke and cancer) expand; because these conditions could be effectively and efficiently taken care of at home with appropriate and targeted support, the relevance of home healthcare activities is globally increasing [28]. Since the earliest reports, HHWs were suspected to be at increased risk for MSD compared to other care-giving occupations [9,25,26], but several uncertainties still remain [14,21,22]. Actually, lower back injuries were described as more frequent in home care settings than in hospital settings, and a significant evidence suggests that HHWs provide more physical care

Table 5. Multivariate regression analysis for neck/back pain (NBP) including only grade 2 or $3^{*}$ identified in study groups - residential healthcare workers (HCWs) subdivided by exposure as assessed by MAPO [29-31] and home-based healthcare workers (HHWs) - and controls (administrative workers)

\begin{tabular}{|c|c|c|c|c|}
\hline \multirow{2}{*}{ Exposure group } & \multirow{2}{*}{$\mathrm{p}$} & \multirow{2}{*}{$\mathrm{OR}_{\mathrm{adj}}$} & \multicolumn{2}{|c|}{$95 \% \mathrm{CI}$} \\
\hline & & & LL & UL \\
\hline Administrative workers (reference) & 1.000 & 1.000 & - & - \\
\hline \multicolumn{5}{|l|}{ HCWs } \\
\hline MAPO 0-5 & 0.034 & 2.222 & 1.063 & 4.647 \\
\hline $\mathrm{MAPO} \geq 5.01$ & 0.002 & 3.059 & 1.517 & 6.169 \\
\hline HHWs & 0.000 & 3.453 & 1.732 & 6.884 \\
\hline
\end{tabular}

* Grade $2=$ grade 1 (discomfort in the back or in the neck with or without radiation into the leg to below the knee for at least 1 day during the preceding 12 months; physical examination negative) and pain elicited by palpation of paravertebral muscle and/or spinal apophysis; grade $3=$ grade 2 and positivity of direct and/or indirect Lasegue sign, with/without pain at mobilization (active/passive) [30,34,35].

Abbreviations as in Table 4.

$\mathrm{OR}_{\text {adj }}$ were corrected for smoking history, previous pregnancies and ethnic origin. 
to patients than their counterparts in hospital settings, thus seemly explaining the higher prevalence of NBP in HHWs [21-23,33,38,39].

Developing or adapting appropriate risk assessment tools is therefore not only useful, but also even indispensable to a reliable understanding of the MSD issue [16,29,30], hopefully allowing HHWs to work healthier and longer. In the global shortage of nursing professionals, this is not only an ethical issue, but also represents a basis for the sustainability of advanced healthcare systems [40-42]. In general, our findings showed a prevalence of MDS in HCWs similar to the other Italian reports [29-31], but relatively lower than in previous studies on HHWs [9,24,25]. More in details, our results confirmed a relevant prevalence of NBP/ULS (28.3\%) in HCWs: HHWs (31\%) and residential HCWs (34\%) exposed to MAPO $\geq 5.01$ showed a significantly higher prevalence of NBP, not only with respect to reference group, but also with respect to HCWs exposed to a lower MAPO index. Moreover, HHWs more frequently reported lumbosacral MSD, whereas ULS were more frequently identified in residential HCWs.

In other words, MAPO index eventually retained its usefulness in the identification of exposure groups as risk groups, with MAPO $\geq 5.01$ associated with a significantly higher prevalence of NBP: as prevalence of MSD was similar in HHWs and in HCWs having a MAPO $\geq 5.01$, the risk for NBP/USL may be regarded as similar [30,31].

However, several cautionary remarks are in need. For instance, the very prevalence of work-related MSD in HCWs still remains a matter of debate. On the one hand, HCWs exposure to patient handling is variable among the institutions and within the same institutions, and all the available analytical methods (i.e., PTAI, MAPO, TilThermometer and Dortmund) are encumbered with specific limitations [21,27-29]. On the other hand, MDS and mainly NBP/ ULS (in particular, in lumbosacral region) are very common, subjective complaints, with different case definition
[14,43-46]. Because of the relatively reduced study population, statistical power analysis suggest that our result may be insufficient to draw more general conclusions. However, as previously stated, in occupational medicine researches a solid study design with rigorous case definition, selection of participants and good matching may often compensate such limitations [47].

Furthermore, the disorders underlying MSD are often unclear: few cases are clearly associated, for example, with herniated inter-vertebral disc or compression of the median nerve in the carpal tunnel, and more frequently MSD represent a collection of unclear and "non-specific" symptoms [45,46,48].

Eventually, some reviews have hinted that occupational exposure may be not important in the aetiology of back pain in general and in HCWs in particular, contradicting both a huge amount of experimental laboratory studies showing evidence of short-term and long-term effects of manual handling on NBP, and a large previous base of evidence [48-51]. These contradictory results are probably due to erratic case definitions in a setting of general over-reporting [14]. Indeed, MDS in occupational settings are suspected to be largely over-referred, in particular in certain European countries (i.e., Italy, France, Belgium and Luxemburg), where a statutory presumptive etiological plausibility is assumed for several MDS, and the workers, in order to achieve an economic compensation, only need to demonstrate that they are suffering from listed disease and that they have incurred the actual exposure during work tasks, or that they have done specified jobs. Again, because several National legislations for Health and Safety (in Italy, Legislative Decree No. 81/2008 [52]) are very protective towards employees with impaired medical fitness to work, MDS complaints might cause that the affected workers are assigned less physically demanding tasks, becoming instrumental to improvement of work position. As a consequence, fully anamnesis-based reports not supported by results of a physical evaluation of subjects should be critically assessed. 
Since SIMLII guidelines were designed in order to assist the occupational physician in a more evidence-based assessment of MSD, the present study retained these case definitions (Table 1) in order to reduce the risk of overdiagnosis [32,34,35]. Moreover, previous trauma of neck, back or upper limb was identified as an exclusion criterion $[14,45,49]$. Collectively, these remarks may explain the relatively lower prevalence of MSD in this sample compared to previous studies on HHWs [9,25,26].

Another limitation of the study stems from its design, not focusing on the specific risk factors associated with the different healthcare activities. In particular, psychological elements, whose relevance was more recently identified, were not taken in account [12,13,29,53-55]. In other words, this research does not contribute to a more accurate understanding of the MDS causes among HHWs, and only general hints may be suggested for preventive programs [21].

\section{CONCLUSIONS}

Our study, stressing the higher prevalence for MSD in HHWs with respect to a reference population and also to a low-risk patient handling exposure group, suggests that HHWs risk for NBP/USL may be conceived as similar to resident workers exposed to MAPO $\geq 5.01$. More in details, HHWs exhibit a higher risk for lumbosacral involvement, whereas the ULS are more frequently reported by residential workers exposed to higher MAPO indices. Medical surveillance of these subjects requires the same level of attention usually applied to HCWs from the more physical demanding residential settings. In other words, occupational medical professionals and HCWs managers have to be aware that re-assignment of HCWs with limited or even hindered medical fitness to work to the home healthcare service not only will not improve the subjects' interaction with working requirements, but reasonably will be detrimental in even short terms, and therefore should be avoided.

\section{REFERENCES}

1. Hoy D, Bain C, Williams G, March L, Brooks P, Blyth F, et al. A systematic review of the global prevalence of low back pain. Arthritis Rheum. 2012;64(6):2028-37, https://doi.org/ 10.1002/art.34347.

2. Hoy D, Brooks P, Blyth F, Buchbinder R. The epidemiology of low back pain. Best Pract Res Clin Rheumatol. 2010;24(6):769-81, https://doi.org/10.1016/j.berh.2010. 10.002 .

3. Andersson GB. Epidemiological features of chronic lowback pain. Lancet. 1999;354(9178):581-5, https://doi.org/ 10.1016/S0140-6736(99)01312-4.

4. Riccò M, Cattani S, Gualerzi G, Signorelli C. Work with visual display units and musculoskeletal disorders: A crosssectional study. Med Pr. 2016;67(6):707-19, https://doi.org/ 10.13075/mp.5893.00471.

5. Riccò M, Cattani S, Signorelli C. Personal risk factors for carpal tunnel syndrome in female visual display unit workers. Int J Occup Med Environ Health. 2016;29(6):927-36, https://doi.org/10.13075/ijomeh.1896.00781.

6. Moreira RFC, Sato TO, Foltran FA, Silva LCCB, Coury HJCG. Prevalence of musculoskeletal symptoms in hospital nurse technicians and licensed practical nurses: Associations with demographic factors. Braz J Phys Ther. 2014;18(4):32333, https://doi.org/10.1590/bjpt-rbf.2014.0026.

7. Karahan A, Kav S, Abbasoglu A, Dogan N. Low back pain: Prevalence and associated risk factors among hospital staff. J Adv Nurs. 2009;65(3):516-24, https://doi.org/10.1111/j.13 65-2648.2008.04905.x.

8. Bejia I, Younes M, Jamila HB, Khalfallah T, Ben Salem K, Touzi M, et al. Prevalence and factors associated to low back pain among hospital staff. Joint Bone Spine. 2005;72(3): 254-9, https://doi.org/10.1016/j.jbspin.2004.06.001.

9. Jensen RC. Disabling back injuries among nursing personnel: Research needs and justification. Res Nurs Health. 1987;10(1):29-38, https://doi.org/10.1002/nur.4770100106.

10. Holtermann A, Clausen T, Jørgensen MB, Burdorf A, Andersen LL. Patient handling and risk for developing 
persistent low-back pain among female healthcare workers. Scand J Work Environ Health. 2012;39(2):164-9, https://doi. org/10.5271/sjweh.3329.

11. Andersen LL, Clausen T, Mortensen OS, Burr H, Holtermann A. A prospective cohort study on musculoskeletal risk factors for long-term sickness absence among healthcare workers in eldercare. Int Arch Occup Environ Health. 2011;85(6): 615-22, https://doi.org/10.1007/s00420-011-0709-5.

12. Simon M, Tackenberg P, Nienhaus A, Estryn-Behar M, Conway PM, Hasselhorn H-M. Back or neck-pain-related disability of nursing staff in hospitals, nursing homes and home care in 7 countries: Results from the European NEXT-Study. Int J Nurs Stud. 2008;45(1):24-34, https://doi.org/10.1016/ j.jinurstu.2006.11.003.

13. Hignett S. Work-related back pain in nurses. J Adv Nurs. 1996;23(6):1238-46, https://doi.org/10.1046/j.1365-26 48.1996.13423.x.

14. Yassi A, Lockhart K. Work-relatedness of low back pain in nursing personnel: A systematic review. Int J Occup Environ Health. 2013;19(3):223-44, https://doi.org/10.1179/20493967 13Y.0000000027.

15. Tullar JM, Brewer S, Amick BC, Irvin E, Mahood Q, Pompeii LA, et al. Occupational safety and health interventions to reduce musculoskeletal symptoms in the health care sector. J Occup Rehabil. 2010;20(2):199-219, https://doi.org/ 10.1007/s10926-010-9231-y.

16. Jager M, Jordan C, Theilmeier A, Wortmann N, Kuhn S, Nienhaus A, et al. Lumbar-load analysis of manual patienthandling activities for biomechanical overload prevention among healthcare workers. Ann Occup Hyg. 2013;57(4): 528-44, https://doi.org/10.1093/annhyg/mes088.

17. Schibye B, Hansen AF, Hye-Knudsen CT, Essendrop M, Böcher M, Skotte J. Biomechanical analysis of the effect of changing patient-handling technique. Appl Ergon. 2003;34(2):115-23, https://doi.org/10.1016/S0003-6870(03) 00003-6.

18. Skotte J, Essendrop M, Hansen AF, Schibye B. A dynamic 3D biomechanical evaluation of the load on the low back during different patient-handling tasks. J Biomech.2002;35(10):1357-66, https://doi.org/10.1016/S0021-92 90(02)00181-1.

19. Burdorf A, Koppelaar E, Evanoff B. Assessment of the impact of lifting device use on low back pain and musculoskeletal injury claims among nurses. Occup Environ Med. 2013;70(7):491-7, https://doi.org/10.1136/oemed2012-101210.

20. Horneij EL, Jensen IB, Holmström EB, Ekdahl C. Sick leave among home-care personnel: A longitudinal study of risk factors. BMC Musculoskelet Disord. 2004;5(1):38, https:// doi.org/10.1186/1471-2474-5-38.

21. Cheung K, Gillen M, Faucett J, Krause N. The prevalence of and risk factors for back pain among home care nursing personnel in Hong Kong. Am J Ind Med. 2005;49(1):14-22, https://doi.org/10.1002/ajim.20243.

22. Galinsky T, Waters T, Malit B. Overexertion injuries in home health care workers and the need for ergonomics. Home Health Care Serv Q. 2002;20(3):57-73, https://doi.org/10. 1300/J027v20n03_04.

23. Myers A, Jensen RC, Nestor D, Rattiner J. Low back injuries among home health aides compared with hospital nursing aides. Home Health Care Serv Q. 1993;14(2-3):149-55, https://doi.org/10.1300/J027v14n02_11.

24. Ono Y, Lagerström M, Hagberg M, Linden A, Malker B. Reports of work related musculoskeletal injury among home care service workers compared with nursery school workers and the general population of employed women in Sweden. Occup Environ Med. 1995;52(10):686-93, https://doi. org/10.1136/oem.52.10.686.

25. Knibbe JJ, Friele RD. Prevalence of back pain and characteristics of the physical workload of community nurses. Ergonomics. 1996;39(2):186-98, https://doi.org/10. 1080/00140139608964450.

26. Moens GF, Dohogne T, Jacques P, van Helshoecht P. Back pain and its correlates among workers in family care. Occup Med. 1993;43(2):78-84, https://doi.org/10.1093/occmed/ 43.2.78. 
27. World Health Organization. Home care across Europe: Current structure and future challenges. Genet N, Boerma W, Kroneman M, Hutchinson A, Saltman RB, editors. Copenhagen: The Organization; 2012. p. 1-156.

28. Tarricone R, Tsouros AD, editors. Home care in Europe. Copenhagen: World Health Organization; 2008. p. 1-46.

29. ISO/TR 12296:2012(E). Ergonomics - Manual handling of people in the healthcare sector. Geneva: International Organization for Standardization; 2012. p. 1-98.

30. Battevi N, Menoni O, Ricci MG, Cairoli S. MAPO index for risk assessment of patient manual handling in hospital wards: A validation study. Ergonomics. 2006;49(7):671-87, https://doi.org/10.1080/00140130600581041.

31. Battevi N, Menoni O. Screening of risk from patient manual handling with MAPO method. Work. 2012;41 Suppl 1: 1920-7, https://doi.org/10.3233/WOR-2012-0408-1920.

32. Occhipinti E, Colombini D, Molteni G, Menoni O, Boccardi A, Grieco A. [Development and validation of a questionnaire in the study of spinal changes in a working population]. Med Lav. 1988;79(5):390-402. Italian.

33. Buckup K. Clinical tests for the musculoskeletal system: Examination, signs, phenomena. Stuttgart, New York: Thieme Publisher; 2004.

34. Violante FS, Bonfiglioli R, Mattioli S, Baldasseroni A, Baratti A, Bazzini G, et al. [Guidelines on the prevention of disorders correlated to manual handling of patients]. Pavia: Società Italiana di Medicina del Lavoro ed Igiene Industriale (SIMLII); 2008. p. 1-141. Italian.

35. Colombini D, Occhipinti E, Menoni O, Bonaiuti D, Cantoni S, Molteni G, et al. [Diseases of the dorsal-lumbar spine and manual handling of loads: Guidelines for fitness assessment]. Med Lav. 1993;84(5):373-8. Italian.

36. Rawaf S, De Maeseneer J, Starfield B. From Alma-Ata to Almaty: A new start for primary health care. Lancet. 2008;372(9647):1365-7, https://doi.org/10.1016/S0140-6736 (08)61524-X.

37. Lawn JE, Rohde J, Rifkin S, Were M, Paul VK, Chopra M. Alma-Ata 30 years on: Revolutionary, relevant, and time to revitalise. Lancet. 2008;372(9642):917-27, https://doi.org/ 10.1016/S0140-6736(08)61402-6.

38. Meyer JD, Muntaner C. Injuries in home care workers: An analysis of occupational morbidity from a state compensation database. Am J Ind Med. 1999;35(3):295-301, https:// doi.org/10.1002/(SICI)1097-0274(199903)35:3<295::AIDAJIM10>3.0.CO;2-\#.

39. Howard N, Adams D. An analysis of injuries among home health care workers using the Washington state workers' compensation claims database. Home Health Care Serv Q. 2010;29(2):55-74, https://doi.org/10.1080/01621424.2010. 493435 .

40. Manzano-García G, Ayala-Calvo J-C. An overview of nursing in Europe: A SWOT analysis. Nurs Inq. 2014;21(4): 358-67, https://doi.org/10.1111/nin.12069.

41. Gottlieb LM. Learning from Alma Ata: The medical home and comprehensive primary health care. J Am Board Fam Med. 2009;22(3):242-6, https://doi.org/10.3122/jabfm.2009.03.080195.

42. Buchan J, O’May F, Dussault G. Nursing workforce policy and the economic crisis: A global overview. J Nurs Scholarsh. 2013;45(3):298-307, https://doi.org/10.1111/jnu.12028.

43. Airaksinen O, Brox JI, Cedraschi C, Hildebrandt J, KlaberMoffett J, Kovacs F, et al. Chapter 4. European guidelines for the management of chronic nonspecific low back pain. Eur Spine J. 2006 Mar;15 Suppl 2:s192-300, https://doi. org/10.1007/s00586-006-1072-1.

44. Krismer M, van Tulder M. Low back pain (non-specific). Best Pract Res Clin Rheumatol. 2007;21(1):77-91, https:// doi.org/10.1016/j.berh.2006.08.004.

45. Coggon D, Ntani G, Palmer KT, Felli VE, Harari R, Barrero L, et al. Disabling musculoskeletal pain in the working populations: Is it the job, the person or the culture. Pain. 2013;154(6):856-63, https://doi.org/10.1016/j.pain.20 13.02.008.

46. Griffith LE, Hogg-Johnson S, Cole DC, Krause N, Hayden J, Burdorf A, et al. Low-back pain definitions in occupational studies were categorized for a meta-analysis using Delphi 
consensus methods. J Clin Epidemiol. 2007;60(6):625.e1-23, https://doi.org/10.1016/j.jclinepi.2006.09.005.

47. Checkoway H, Pearce N, Crawford-Brown DJ. Research methods in occupational epidemiology. New York: Oxford University Press; 1999.

48. Van Tulder M, Becker A, Bekkering T, Breen A, del Real MT, Hutchinson A, et al. Chapter 3. European guidelines for the management of acute nonspecific low back pain in primary care. Eur Spine J. 2006;15 Suppl 2:S169-91, https:// doi.org/10.1007/s00586-006-1071-2.

49. Kwon BK, Roffey DM, Bishop PB, Dagenais S, Wai EK. Systematic review: Occupational physical activity and low back pain. Occup Med. 2011;61(8):541-8, https://doi.org/10.1093/ occmed/kqr092.

50. Wai EK, Roffey DM, Bishop P, Kwon BK, Dagenais S. Causal assessment of occupational bending or twisting and low back pain: Results of a systematic review. Spine J. 2010;10(1): 76-88, https://doi.org/10.1016/j.spinee.2009.06.005.

51. Roffey DM, Wai EK, Bishop P, Kwon BK, Dagenais S. Causal assessment of awkward occupational postures and low back pain: Results of a systematic review. Spine J. 2010;10(1): 89-99, https://doi.org/10.1016/j.spinee.2009.09.003.

52. [The Act No. 81 of 9 April 2008 on health and safety in the workplaces. J Laws (GU) 2008, No. 101, ordinary suppl. No. 108]. Italian.

53. Roffey DM, Wai EK, Bishop P, Kwon BK, Dagenais S. Causal assessment of workplace manual handling or assisting patients and low back pain: Results of a systematic review. Spine J. 2010;10(7):639-51, https://doi.org/10.1016/ j.spinee.2010.04.028.

54. Czuba LR, Sommerich C, Lavender SA. Ergonomics and safety risk factors in home health care: Exploration and assessment of alternative interventions. Work. 2012;42(3):34153, https://doi.org/10.3233/WOR-2012-1433.

55. Dawson AP, McLennan SN, Schiller SD, Jull GA, Hodges PW, Stewart S. Interventions to prevent back pain and back injury in nurses: A systematic review. Occup Environ Med. 2007;64(10):642-50, https://doi.org/10.1136/ oem.2006.030643.

This work is available in Open Access model and licensed under a Creative Commons Attribution-NonCommercial 3.0 Poland License - http://creativecommons.org/ licenses/by-nc/3.0/pl/deed.en. 